\title{
SORÇÃo do ImazaPYR EM SOlOS COM Diferentes TeXTURAs ${ }^{1}$
}

\author{
Imazapyr Sorption in Soils with Different Textures \\ FIRMINO, L.E. ${ }^{2}$, TUFFI SANTOS, L.D. ${ }^{3}$, FERREIRA, F.A. ${ }^{4}$, FERREIRA, L.R. ${ }^{4}$ e TIBURCIO, R.A.S. ${ }^{5}$ \\ RESUMO - O conhecimento do comportamento de herbicidas no ambiente, sobretudo no \\ solo, permite a predição de possiveis impactos do seu uso em sistemas agrícolas. Com o \\ intuito de avaliar a sorção do herbicida imazapyr no solo, foi realizado um experimento, \\ utilizando sorgo (Sorghum bicolor) como planta bioindicadora. A sorção do imazapyr foi avaliada \\ em areia lavada e em três solos, com as seguintes texturas: muito argilosa, franco-argilo- \\ arenosa e areia-franca, provenientes, respectivamente, das cidades de Sete Lagoas, João \\ Pinheiro e Rio Casca, em Minas Gerais. Foram determinados: o valor de $\mathrm{I}_{50}$ (dose que inibiu \\ $50 \%$ no acúmulo de massa seca da planta-teste) e a relação de sorção $\left[R S=\left(I_{50}\right.\right.$ solo - \\ $\mathrm{I}_{50}$ areia) $/ \mathrm{I}_{50}$ areia]. Os valores de $\mathrm{I}_{50}$ observados foram: 29,41;10,20 e 7,33 $\mu \mathrm{g} \mathrm{kg-1}$, e a relação \\ de sorção (RS): 9,77; 2,73 e 1,68, respectivamente para os solos muito argiloso, franco- \\ argilo-arenoso e areia franca. O herbicida imazapyr apresentou a seguinte ordem de sorção \\ nos substratos: muito argiloso > franco-argilo-arenoso > areia-franca > areia lavada. Em \\ solos arenosos e com baixos teores de matéria orgânica, a baixa sorção do imazapyr predispõe \\ o produto à lixiviação no perfil do solo, podendo contaminar mananciais de águas \\ subterrâneas.
}

Palavras-chave: potencial de lixiviação, bioensaio, herbicida.

ABSTRACT - Knowledge about herbicide behavior in the environment, especially in soil, allows predicting possible impacts caused by its use in agricultural systems. An experiment using Sorghum bicolor as a bio-indicator was carried out to evaluate imazapyr sorption in soil. Sorption was evaluated in washed sand and in soils of 3 different textures: very clayed, sandy clayed loam and sandy loam, respectively from Sete Lagoas, João Pinheiro and Rio Casca-Minas Gerais. The value of $I_{50}$, which inhibits 50\% of dry biomass accumulation of the test-plant, and sorption relation (SR $=I_{50}$ soil $-I_{50}$ sand $/ I_{50}$ sand) were determined. $I_{50}$ values observed were $29.41,10.20$ and $7.33 \mathrm{mg} \mathrm{kg}^{-1}$ and SR values were 9.77, 2.73 and 1.68, respectively for very clayed, sandy clayed loam and sandy loam soils. The order of substrate sorption presented by imazapyr was very clayed > sandy clay loam > sandy loam > washed sand. In sandy soil and soil with low organic matter content, low imazapyr sorption predisposes the product to leaching, and it may contaminate the underground water.

Keywords: leaching potential, bioassay, herbicide.

\section{INTRODUÇÃO}

A sorção e a dessorção de herbicidas no solo regulam o fenômeno de retenção, influenciando o transporte, a transformação e a biodisponibilidade dessas moléculas no solo. A sorção dos herbicidas está correlacionada com as propriedades do solo, as quais devem ser consideradas nas recomendações de aplicação desses produtos (Silva et al., 2005). A sorção de herbicidas na superficie dos colóides orgânicos e minerais do solo explica parte do comportamento apresentado por essas moléculas, dentro das diversas classes de solo, tornando-se

Recebido para publicação em 4.9.2007 e na forma revisada em 31.3.2008.

2 Mestre em Fitotecnia; ${ }^{3}$ Pós-Doutorado do Dep. de Fitotecnia, bolsista CNPq, <ltuffi@yahoo.com.br>; ${ }^{4}$ Professor do Dep. de Fitotecnia, bolsista CNPq; ${ }^{5}$ Mestrando em Fitotecnia. Universidade Federal de Viçosa, Dep. de Fitotecnia, Av. P. H. Rolfs, s/n, 36570-000 Viçosa-MG. 
dificil predizer o comportamento desses agrotóxicos sem antes conhecer os fatores que agem sobre eles.

Os herbicidas do grupo químico das imidazolinonas apresentam longa persistência no solo, podendo causar intoxicação às culturas posteriores (Gennari et al., 1998). Por isso, são de importância o estudo e o entendimento do comportamento dessa classe de herbicida em solos de ambientes tropicais.

O imazapyr apresenta amplo espectro de ação, controlando plantas daninhas mono e dicotiledôneas. Normalmente, é aplicado em pós-emergência, apresentando ação residual longa, que pode variar em função da dose utilizada, do tipo de solo e das condições ambientais (Rodrigues \& Almeida, 2005). Por causa da presença do ácido carboxillico e do grupo funcional básico da piridina, o imazapyr apresenta comportamento no solo dependente do $\mathrm{pH}$. Além do $\mathrm{pH}$, os teores de matéria orgânica e óxidos de ferro são importantes para entender o movimento desse produto no solo, uma vez que os processos de dessorção são diretamente influenciados por essas características do substrato (Pusino et al., 1997).

A persistência do imazapyr no solo depende da dose aplicada, das condições pluviométricas na região, do $\mathrm{pH}$, da textura, da umidade e do tipo de argila presente no solo (Ismail \& Ahmad, 1994). Na literatura, a atividade herbicida tem sido relatada de três meses a dois anos, em condições de clima temperado, entretanto, sua meia-vida é baixa $(2,7$ e 2,9 dias) em pH 5 e 9, respectivamente (Mallipudi et al., 1991), em função da maior adsorção do herbicida nessas condições de $\mathrm{pH}$ (Gennari et al., 1998). Por outro lado, Ahrens (1994) observou que a meia-vida de decomposição fotolítica, em água destilada com pH 9, foi de 1,3 dia. Curran et al. (1992) observaram degradação de $100 \%$ do imazapyr presente em solução aquosa 48 horas após a exposição à luz ultravioleta. A adsorção de imazapyr pode variar em função da carga do componente adsorvente, da presença de matéria orgânica e de óxidos de ferro amorfo (Pusino et al., 1997). Também, a maior presença de argila no substrato reduz a meia-vida do imazapyr de sete para cinco dias (Ismail \& Ahmad, 1994).
Em razão da grande variabilidade nas características física, química e biológica entre os solos, é esperado que a natureza e a intensidade dos processos de sorção também sejam distintas. Assim, é de fundamental importância o conhecimento das características físicoquímicas do solo para que se possa estimar o comportamento do herbicida no ambiente, o que possibilita seu uso correto, a minimização dos impactos ambientais e a maior eficiência na utilização do produto.

Objetivou-se, com a realização deste trabalho, avaliar a sorção de imazapyr em três solos de caracteristicas físicas e químicas distintas.

\section{MATERIAL E MÉTODOS}

Os experimentos foram conduzidos em casa de vegetação, no campus da Universidade Federal de Viçosa. Foram utilizados quatro substratos, sendo três solos: muito argiloso, franco-argilo-arenoso e areia-franca, provenientes, respectivamente, de Sete Lagoas, João Pinheiro e Rio Casca, em Minas Gerais, caracterizados física e quimicamente na Tabela 1 , e areia lavada, a qual foi considerada como material inerte. Os ensaios foram conduzidos simultaneamente, de forma independente para cada substrato.

A areia foi peneirada em malha de $2 \mathrm{~mm}$, sendo em seguida tratada, durante 36 horas, com ácido clorídrico PA, diluído em água, numa proporção de $600 \mathrm{~mL}$ de ácido para cada $10 \mathrm{~L}$ de água, mantendo-se lâmina de $10 \mathrm{~cm}$ da solução ácida acima do nível da areia, em baldes de polietileno. Após esse período, a areia foi lavada com água corrente, até que fosse retirado o excesso de ácido, alcançando o $\mathrm{pH}$ próximo de 7,0 em água deionizada. A areia lavada foi utilizada para elaboração da curva-padrão de sorção.

Após serem peneirados e secos à sombra, os substratos foram colocados em vasos plásticos com capacidade para $100 \mathrm{~cm}^{3}$. A massa dos substratos (solos e areia) foi igual para todos os vasos, dentro do mesmo tipo de substrato (Tabela 2). Após o preenchimento dos vasos, foram semeadas seis sementes de sorgo BR 007 (Sorghum bicolor), por vaso, a uma profundidade de $1,5 \mathrm{~cm}$. Em seguida, aplicou-se o imazapyr na superficie dos substratos, por 
Tabela 1 - Resultados das análises química e física das amostras dos solos provenientes de Sete Lagoas (SL), João Pinheiro (JP) e Rio Casca (RC), no Estado de Minas Gerais

\begin{tabular}{|c|c|c|c|c|c|c|c|c|}
\hline \multicolumn{9}{|c|}{ Caracterização química } \\
\hline \multirow{2}{*}{ Origem do solo } & \multirow{2}{*}{$\mathrm{pH} \mathrm{H} \mathrm{H}_{2} \mathrm{O}$} & $\mathrm{P}$ & $\mathrm{K}^{+}$ & A & $\mathrm{H}+\mathrm{Al}$ & $\mathrm{Ca}^{2+}$ & $\mathrm{Mg}^{2+}$ & $\mathrm{CO}$ \\
\hline & & \multicolumn{2}{|c|}{------- $\mathrm{mg} \mathrm{dm}^{-3}$------- } & \multicolumn{4}{|c|}{------------------------ $\mathrm{cmol}_{\mathrm{c}} \mathrm{dm}^{-3}$---------------------- } & -- dag $\mathrm{kg}^{-1}--$ \\
\hline SL & 5,21 & 3,36 & 80 & & 9,60 & 1,04 & 0,19 & 3,20 \\
\hline JP & 4,95 & 1,20 & 30 & & 4,50 & 0,10 & 0,35 & 1,20 \\
\hline \multirow[t]{3}{*}{$\mathrm{RC}$} & 6,28 & 2,77 & 69 & & 1,32 & 2,29 & 0,73 & 1,14 \\
\hline & \multicolumn{2}{|c|}{ Fe Oxalato } & \multicolumn{3}{|c|}{ Fe Ditionito } & \multicolumn{3}{|c|}{ P Remanescente } \\
\hline & \multicolumn{5}{|c|}{ 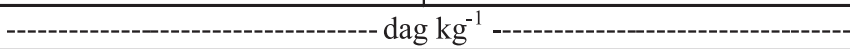 } & \multicolumn{3}{|c|}{ 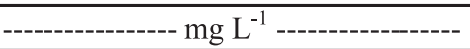 } \\
\hline SL & \multicolumn{2}{|c|}{0,57} & \multicolumn{3}{|c|}{6,84} & \multicolumn{3}{|c|}{5,18} \\
\hline JP & \multicolumn{2}{|c|}{0,41} & \multicolumn{3}{|c|}{5,65} & \multicolumn{3}{|c|}{18,09} \\
\hline $\mathrm{RC}$ & \multicolumn{2}{|c|}{0,08} & \multicolumn{3}{|c|}{0,42} & \multicolumn{3}{|c|}{39,70} \\
\hline \multicolumn{9}{|c|}{ Caracterização física } \\
\hline & Argila & \multirow{2}{*}{ Silte } & \multicolumn{2}{|c|}{ Areia fina } & Areia grossa & \multirow{2}{*}{\multicolumn{3}{|c|}{ Classificação textural }} \\
\hline & \multicolumn{4}{|c|}{-------------------------------- dag kg ${ }^{-1}$-------------------------------------- } & & & & \\
\hline SL & 81 & 5 & \multicolumn{2}{|c|}{5} & 9 & \multicolumn{3}{|c|}{ Muito argilosa } \\
\hline JP & 30 & 6 & \multicolumn{2}{|c|}{22} & 42 & \multicolumn{3}{|c|}{ Franco-argilo-arenosa } \\
\hline $\mathrm{RC}$ & 10 & 5 & & & 76 & \multicolumn{3}{|c|}{ Areia-franca } \\
\hline
\end{tabular}

Análises realizadas nos Laboratórios de Análises Físicas e Químicas de Solo do Departamento de Solos da UFV.

Tabela 2 - Massa de solo utilizada, intensidade de chuva simulada após a aplicação do herbicida e teor de água (em base gravimétrica) mantido ao longo da realização do experimento

\begin{tabular}{|l|c|c|c|}
\hline \multicolumn{1}{|c|}{ Solo $^{1}$} & $\begin{array}{c}\text { Massa } \\
(\mathrm{g})\end{array}$ & $\begin{array}{c}\text { Intensidade de } \\
\text { Chuva }(\mathrm{mm})\end{array}$ & $\begin{array}{c}\text { Teor de água } \\
\left(\mathrm{dag} \mathrm{kg}^{-1}\right)\end{array}$ \\
\hline Areia & 170 & 6 (por 4 min.) & 10,00 \\
\hline Areia-franca (RC) & 150 & 10 (por 7 min.) & 12,00 \\
\hline Franco-argilo-arenoso (JP) & 145 & 10 (por 7 min.) & 12,41 \\
\hline Muito argiloso (SL) & 100 & 10 (por 7 min.) & 40,00 \\
\hline
\end{tabular}

meio de uma seringa de $5 \mathrm{~mL}$, adaptada, com a extremidade da agulha em forma de leque. Em cada substrato foram avaliadas sete doses do herbicida (Tabela 3), definidas previamente após realização de ensaios preliminares. $\mathrm{O}$ delineamento experimental utilizado foi o inteiramente casualizado, sendo sete tratamentos (doses) com quatro repetições, para cada substrato avaliado.

Imediatamente após a aplicação dos tratamentos, simulou-se uma irrigação de $10 \mathrm{~mm}$, durante sete minutos, nos vasos com solo, e de $6 \mathrm{~mm}$, por quatro minutos, nos vasos com areia, em todos os tratamentos. Doze horas após a aplicação dos tratamentos, todos os vasos foram levados à balança, para complementação e ajuste do teor de água em cada um deles
Tabela 3 - Doses de imazapyr aplicadas nos diferentes solos provenientes de Sete Lagoas (SL), João Pinheiro (JP) e Rio Casca (RC), no bioensaio de sorção

\begin{tabular}{|c|c|c|c|c|c|c|c|}
\hline $\begin{array}{c}\text { Muito argiloso } \\
\text { (SL) }\end{array}$ & \multicolumn{2}{c|}{$\begin{array}{c}\text { Franco-argilo- } \\
\text { arenoso (JP) }\end{array}$} & \multicolumn{2}{c|}{$\begin{array}{c}\text { Areia-franca } \\
\text { (RC) }\end{array}$} & \multicolumn{2}{c|}{ Areia } \\
\hline$\mu \mathrm{g} \mathrm{kg}^{-1}$ & $\mu \mathrm{g} \mathrm{k}^{-1}$ & $\mu \mathrm{g} \mathrm{kg}^{-1}$ & $\mu \mathrm{g} \mathrm{kg}^{-1}$ & $\mu \mathrm{g} \mathrm{kg}^{-1}$ & $\mu \mathrm{g} \mathrm{kg}^{-1}$ & $\mu \mathrm{g} \mathrm{k}^{-1}$ & $\mu \mathrm{g} \mathrm{kg}^{-1}$ \\
\hline 0 & 0 & 0 & 0 & 0 & 0 & 0 & 0 \\
\hline 1,6 & 16,0 & 0,6 & 4,1 & 0,4 & 2,7 & 0,1 & 0,6 \\
\hline 2,0 & 20,0 & 0,8 & 5,5 & 0,6 & 4,0 & 0,2 & 1,2 \\
\hline 2,4 & 24,0 & 1,2 & 8,3 & 0,8 & 5,3 & 0,4 & 2,4 \\
\hline 2,8 & 28,0 & 1,6 & 11,0 & 1,2 & 8,0 & 0,6 & 3,5 \\
\hline 3,2 & 32,0 & 2,0 & 13,8 & 1,6 & 10,7 & 0,8 & 4,7 \\
\hline 3,6 & 36,0 & 2,4 & 16,6 & 2,0 & 13,3 & 1,2 & 7,1 \\
\hline
\end{tabular}

(Tabela 2). O teor de água do solo foi mantido próximo à capacidade de campo por meio de pesagens diárias, com reposição da água perdida até a colheita das plantas, para permitir o seu máximo desenvolvimento e a maior disponibilidade do herbicida na solução do solo. As irrigações para manutenção da umidade dos vasos foram feitas três a quatro vezes ao dia. A cada três dias, foi feita uma aplicação de solução nutritiva comercial, contendo $15 \%$ de $\mathrm{N}$, $15 \%$ de $\mathrm{P}_{2} \mathrm{O}_{5}$ e $20 \%$ de $\mathrm{K}_{2} \mathrm{O}$, com macronutrientes secundários e micronutrientes $(\mathrm{Ou}-$ ro Verde 3,0 $\mathrm{g} \mathrm{L}^{-1}$ ), em igual volume para todos os tratamentos.

Planta Daninha, Viçosa-MG, v. 26, n. 2, p. 395-402, 2008 
Aos 21 dias após a semeadura, foi feita a colheita da parte aérea das plantas. O número de plantas por vaso foi anotado e, em seguida, as plantas foram cortadas à altura do coleto, sendo as partes aéreas colocadas em sacos de papel e levadas à estufa de ventilação forçada a $72{ }^{\circ} \mathrm{C}$, por 72 horas, para determinação da biomassa seca.

Os dados foram analisados por meio de análise de regressão. Os modelos foram escolhidos com base no fenômeno biológico e na significância dos coeficientes de regressão, utilizando-se o teste " $\mathrm{t}$ ", adotando-se o nível de 5 e $1 \%$ de probabilidade no coeficiente de determinação.

Com a equação de regressão, determinouse o valor do $\mathrm{I}_{50}$ (concentração do herbicida que reduz em $50 \%$ o acúmulo de massa seca da parte aérea) para os substratos avaliados. Em seguida, utilizando o método proposto por Souza et al. (1996), calculou-se a relação de sorção (RS):

$$
\mathrm{RS}=\frac{\mathrm{I}_{50} \text { solo }-\mathrm{I}_{50} \text { areia }}{\mathrm{I}_{50} \text { areia }}
$$

Segundo Souza et al. (1996), a RS expressa quantas vezes a concentração necessária para reduzir em $50 \%$ o crescimento da planta-teste $\left(\mathrm{I}_{50}\right)$ é sorvida por determinado substrato, em relação ao obtido na areia lavada, considerada como substrato inerte.

\section{RESULTADOS E DISCUSSÃO}

Considerando como zero a sorção no substrato areia lavada, verifica-se que doses de apenas $0,6 \mu \mathrm{g} \mathrm{kg}^{-1}$ foram suficientes para produzir intoxicação aparente nas plantas de sorgo, caracterizadas por cloroses e redução no crescimento (Figura 1). O sorgo (Sorghum bicolor) apresenta alta sensibilidade ao imazapyr, mostrando-se bom bioindicador para este herbicida.

Utilizando a equação ajustada, determinou-se o $\mathrm{I}_{50}$ igual a $2,73 \mathrm{~g} \mathrm{~kg}^{-1}$ de imazapyr para o substrato areia lavada (Figura 1). Neste substrato, pode-se deduzir que uma dose de $5,46 \mathrm{~g} \mathrm{ha}^{-1}$ do imazapyr (disponível no solo), considerando a profundidade de $20 \mathrm{~cm}$ e a densidade igual a 1,0, será suficiente para reduzir

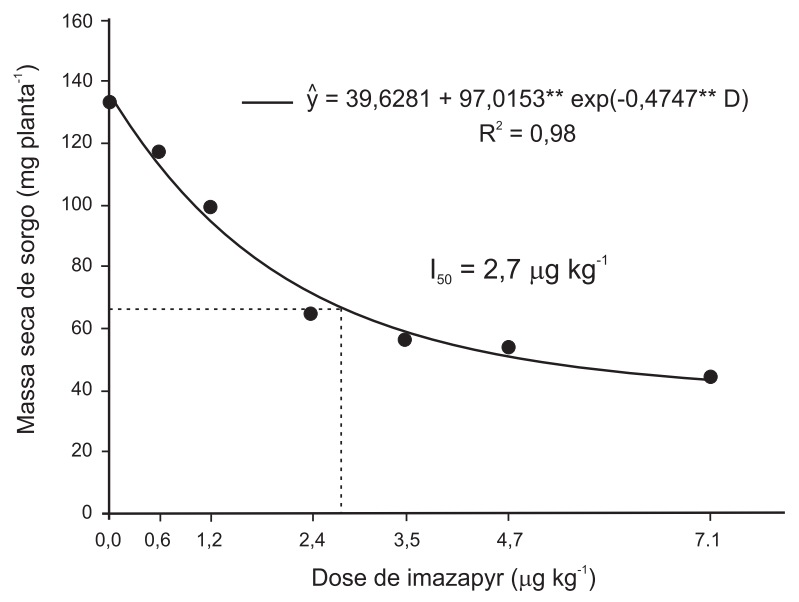

Figura 1 - Massa seca da parte aérea de sorgo cultivado por 21 dias em areia lavada tratada com doses crescentes de imazapyr, aplicado em pré-emergência do bioindicador. ${ }^{* *}$ Significativo a $1 \%$ pelo teste " $\mathrm{t}$ ".

o crescimento em $50 \%$ da planta sensivel (sorgo).

Equações exponenciais decrescentes, com alto ajuste aos dados, foram ajustadas para a massa seca do sorgo em função das doses de imazapyr para o solo muito argiloso (Figura 2), franco-argilo-arenoso (Figura 3) e areia-fraca (Figura 4).

Alta correlação positiva foi encontrada entre a relação de sorção e os teores de matéria orgânica $\left(0,99^{* *}\right)$, argila $\left(0,97^{* *}\right)$, Fe oxálico $\left(0,82^{* *}\right)$ e Fe ditionito $\left(0,73^{*}\right)$ dos três solos avaliados. Contrariamente, houve baixa correlação negativa $\left(-0,44^{\text {ns }}\right)$ entre a relação de sorção e o $\mathrm{pH}$ dos solos. Esses resultados demonstram que para os solos estudados os teores de matéria orgânica, argila e de óxidos de ferro estão diretamente relacionados com a sorção do imazapyr pelo substrato, não havendo correlação desse fenômeno com o pH. Segundo Pusino et al. (1997), trabalhando com solos de clima temperado e, portanto, menos intemperizados, a dessorção do imazapyr depende do $\mathrm{pH}$, da matéria orgânica e dos óxidos de ferro presentes no solo. Estudos realizados por Wang (1999) mostraram que o decréscimo no $\mathrm{pH}$ e o aumento na porcentagem de matéria orgânica do solo aumentam significativamente a sorção do imazapyr.

Maior relação de sorção foi observada para o solo muito argiloso (Sete Lagoas). Este solo apresenta maior percentual de argila 


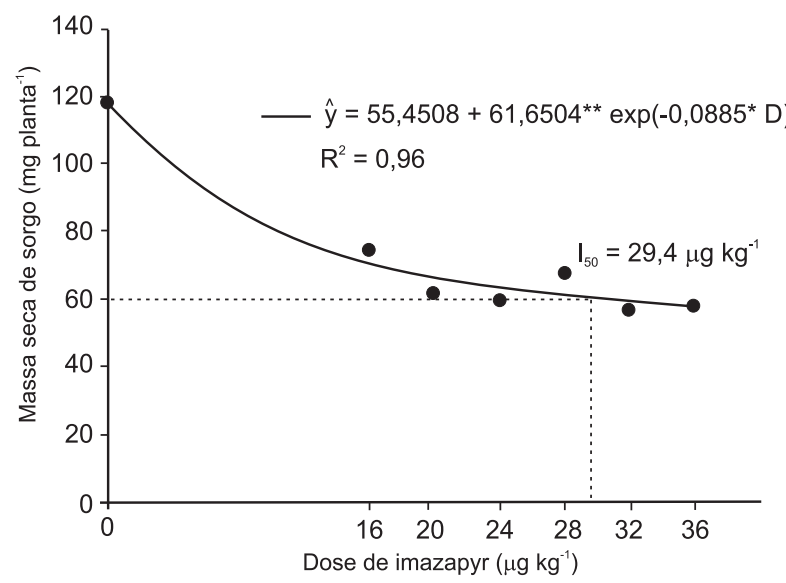

Figura 2 - Massa seca da parte aérea de plantas de sorgo cultivadas por 21 dias no solo muito argiloso, tratado com diferentes doses de imazapyr, aplicado em pré-emergência. ${ }^{* *},{ }^{*}$ Significativo a 1 e $5 \%$, respectivamente, pelo teste $\mathrm{t}$.

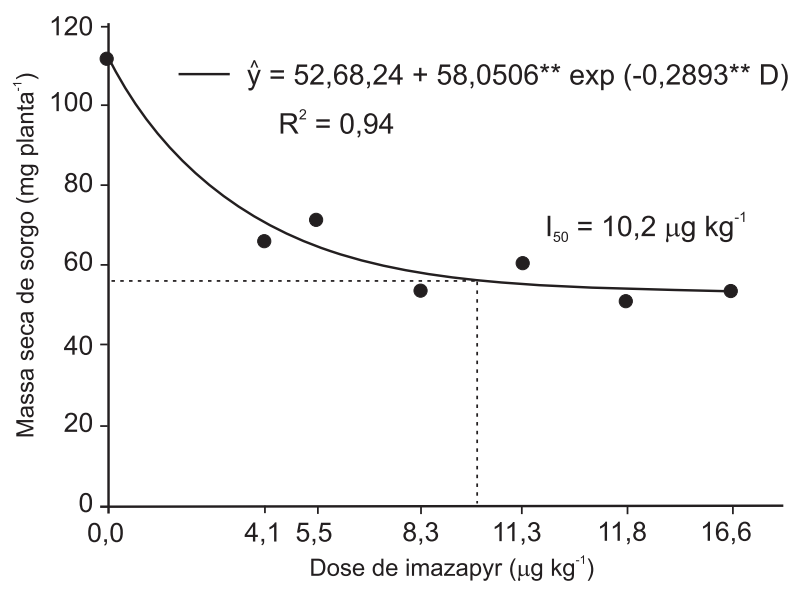

Figura 3 - Massa seca da parte aérea de plantas de sorgo cultivadas por 21 dias no solo franco-argilo-arenoso, tratado com diferentes doses de imazapyr, aplicado em préemergência. ${ }^{* *}$ Significativo a 1 e $5 \%$, pelo teste $\mathrm{t}$.

(81 dag $\left.\mathrm{kg}^{-1}\right)$, matéria orgânica $\left(3,20 \mathrm{dag} \mathrm{kg}^{-1}\right)$ e valor de $\mathrm{pH}$ igual a 5,21. Por causa da presença do ácido carboxílico e do grupo funcional básico da piridina, o imazapyr apresenta três valores de $\mathrm{pKa}(1,9,3,6$ e 11,4), sendo esta uma das características que tornam o comportamento deste herbicida no solo dependente do $\mathrm{pH}$. No $\mathrm{pH}$ encontrado no solo de Sete Lagoas $(5,21)$, a dissociação do íon $\mathrm{H}^{+}$do grupo carboxilico e do anel da imidazolinona, presentes na molécula desse herbicida, pode ser favorecida. Nessa condição, a molécula herbicida passa a apresentar predominantemente cargas negativas, levando-o a interagir com sítios

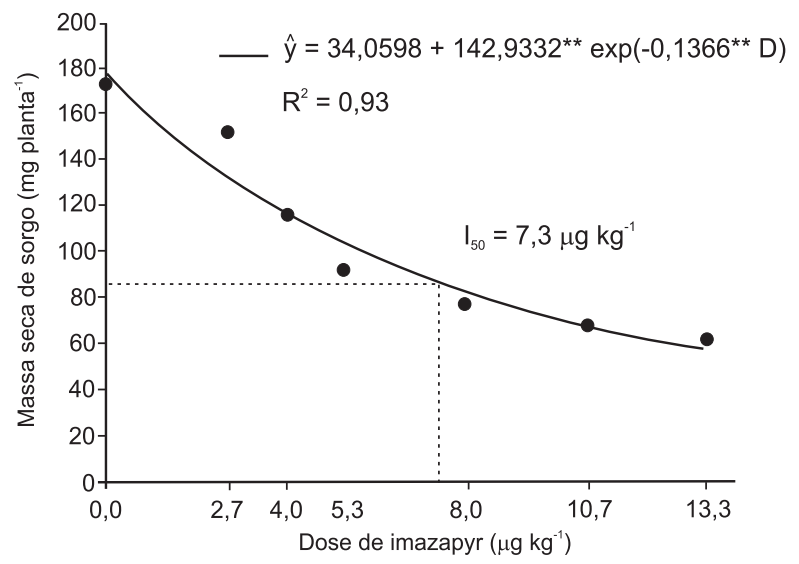

Figura 4 - Massa seca da parte aérea de plantas de sorgo cultivadas por 21 dias no solo areia-franca, tratado com diferentes doses de imazapyr, aplicado em pré-emergência. ${ }^{* *}$ Significativo a $1 \%$ pelo teste $\mathrm{t}$.

positivos da matéria orgânica e de cátions metálicos, como os óxidos de ferro. Esse fato aumentaria a sua interação com a superfície das argilas, ricas em $\mathrm{Fe}$ ditionito e Fe oxalato, e da matéria orgânica do solo, diminuindo sua disponibilidade e aumentando sua sorção nos colóides do solo (Souza et al., 1996).

A relação de sorção do solo franco-argiloarenoso (João Pinheiro) é cerca de três vezes menor que a obtida no substrato muito argiloso (Tabela 4). Esse fato pode ser atribuído, principalmente, ao menor teor de carbono orgânico (CO) $\left(1,20 \mathrm{dag} \mathrm{kg}^{-1}\right)$ e argila (30 dag $\left.\mathrm{kg}^{-1}\right)$ apresentado por este solo, quando comparado ao proveniente de Sete Lagoas (muito argiloso). Segundo Mangels (1991), em valores de pH próximos de 5,0, a forma cationica do imazapyr pode coexistir com a forma anionica. Na forma cationica, este é adsorvido com maior facilidade pela matéria orgânica e por minerais de

Tabela 4 - Doses de imazapyr necessárias para reduzir em $50 \%\left(\mathrm{I}_{50}\right)$ o acúmulo de massa seca da parte aérea de sorgo e relação de sorção (RS) em cada substrato

\begin{tabular}{|l|c|c|}
\hline \multicolumn{1}{|c|}{ Substrato $^{1 /}$} & $\mathrm{I}_{50}\left(\mu \mathrm{g}\right.$ do i.a $\left.\mathrm{kg}^{-1}\right)$ & RS \\
\hline Areia lavada & 2,73 & - \\
\hline Muito argiloso (SL) & 29,41 & 9,77 \\
\hline Franco-argilo-arenoso (JP) & 10,20 & 2,73 \\
\hline Areia-franca (RC) & 7,33 & 1,68 \\
\hline
\end{tabular}

${ }^{1}$ Solos provenientes de Rio Casca (RC), João Pinheiro (JP) e Sete Lagoas (SL). 
argila, ficando menos disponivel na solução do solo. Entretanto, nos solos com maior proporção de areia, a baixa superficie de trocas eletrostáticas proporcionada por esse constituinte do solo pode ser o principal fator relacionado à baixa sorção observada nesses substratos, o que explicaria em parte as diferenças observadas (Tabela 4).

Em geral, solos que possuem altos teores de argila e matéria orgânica, ou ambos, apresentam maior sorção e persistência de herbicidas, seguido por baixos índices de lixiviação e de degradação destes (Li et al., 2003; Si et al., 2006). Entretanto, estudos mais detalhados demonstram que os mecanismos envolvidos com a retenção de herbicidas ocorrem de forma distinta para cada solo e seu ecossistema e que a heterogeneidade desse meio dificulta a previsão de comportamento desses compostos (Pusino et al., 2004). Em trabalho realizado por Procópio et al. (2001), verificou-se que a interação de argilominerais e compostos orgânicos do solo com a formação de complexos adsortivos atuou de forma diferenciada em relação às frações orgânicas ou minerais, enfatizando a necessidade de avaliar os fenômenos de adsorção de herbicidas e os seus riscos de lixiviação em diferentes solos. Embora os herbicidas apresentem características distintas, a matéria orgânica do solo é responsável pelo aumento adsortivo de diversos compostos. Segundo Viera et al. (1999), a matéria orgânica apresenta papel fundamental na adsorção de contaminantes ambientais, como herbicidas e metais pesados, e, como conseqüência, na diminuição da lixiviação destes no perfil dos solos.

Para o solo areia-franca (Rio Casca), a dose requerida de imazapyr para reduzir em $50 \%$ o crescimento da planta-teste $\left(\mathrm{I}_{50}\right)$ foi de $7,33 \mu \mathrm{g} \mathrm{kg}^{-1}$ do substrato, e a razão de sorção (RS) foi igual a 1,68, o que evidencia baixo poder de sorção deste substrato. Esse solo apresenta baixos teores de $\mathrm{CO}\left(1,14 \mathrm{dag} \mathrm{kg}^{1}\right)$ e argila (10 dag $\left.\mathrm{kg}^{-1}\right)$, além de $\mathrm{pH}$ elevado $(6,28)$, o que justifica a menor sorção do herbicida. Todavia, acredita-se que os teores de argila tenham sido o fator mais importante, pois o teor de $\mathrm{CO}$ foi próximo ao observado para o substrato francoargilo-arenoso (JP).

No valor de $\mathrm{pH}$ de 6,28, observado para o solo areia-franca $(\mathrm{RC})$, o imazapyr pode se apresentar na forma aniônica; como os solos intemperizados possuem maior quantidade de cargas negativas, em $\mathrm{pH}$ próximo de 7,0 , a sorção do imazapyr é menor, ficando mais disponível na solução do solo (Souza et al., 2000). Esse fato pode predispor culturas sensiveis à ação desse herbicida quando da realização da calagem em áreas pré-tratadas com eles, principalmente em solos com baixos teores de matéria orgânica e argila.

As doses do imazapyr que causaram 50\% de inibição da produção de massa seca da planta-teste $\left(I_{50}\right)$, calculadas a partir das equações ajustadas, e os respectivos valores de relação de sorção (RS) para cada substrato estão apresentados na Tabela $4 . \mathrm{O} \mathrm{I}_{50}$ apresentou a seguinte ordem decrescente entre os substratos: muito argiloso > franco-argilo-arenoso > areia-franca $>$ areia lavada (Tabela 4). A mesma ordem decrescente foi observada pela razão de sorção (RS) em função dos solos testados (Tabela 4). A razão de sorção do solo muito argiloso $(9,77)$ é, respectivamente, aproximadamente 3,5 e 5,8 vezes maior que a dos solos franco-argilo-arenoso $(2,73)$ e areia-franca $(1,68)$. A razão de sorção igual a 9,77 mostra que o solo muito argiloso apresenta potencial de sorção 9,77 vezes maior do que o substrato considerado inerte (areia lavada).

No Brasil, o imazapyr está registrado para aplicação em pré e pós-emergência das plantas daninhas nas culturas de pínus, seringueira, cana-de-açúcar e também para eliminação de cepas de eucalipto (SINDAG, 2006). No entanto, poucos são os trabalhos na literatura que discutem o destino final da molécula herbicida nesses ecossistemas agrícolas. Na cultura do eucalipto esse produto é registrado para controle da rebrota das cepas, porém o imazapyr aplicado em plantas de Eucalyptus grandis é exsudado e/ou seus metabólitos, pelo sistema radicular das plantas em concentrações capazes de afetar o crescimento de plantas da mesma espécie (Silva et al., 2005). Souza et al. (2006), em trabalho realizado para verificar a exsudação do imazapyr por diferentes clones de E. grandis x E. urophylla (híbrido urograndis), encontraram fitotoxicidade do herbicida em plantas de sorgo cultivadas ao longo do perfil do solo explorado pelo sistema radicular do eucalipto tratado com este produto. Os autores relataram que a exsudação 
aconteceu independentemente do clone de eucalipto testado e que os sintomas de intoxicação nas plantas bioindicadoras foram acentuados com o aumento das doses de imazapyr aplicadas na espécie florestal. A exsudação do imazapyr pelo sistema radicular de plantas tratadas com esse produto pode disponibilizá-lo em camadas mais profundas do solo, em regiões em que os teores de matéria orgânica são, em geral, baixos. Esse fato pode favorecer a disponibilização desse herbicida na solução do solo, predispondo-o à lixiviação e à reabsorção por outras plantas, via sistema radicular.

Aliado ao problema da exsudação, o imazapyr é potencialmente lixiviável. Em avaliação sobre o potencial de lixiviação de herbicidas comercializados no Paraná, de acordo com os critérios teóricos de GUS (Gustafson, 1989), CDFA (Widerson \& Kim, 1986) e Cohen (Cohen et al., 1984), o imazapyr foi classificado como lixiviador pelos três índices (Inoue et al., 2003). O movimento descendente (lixiviação) e ascendente (efeito da capilaridade) do imazapyr com o movimento da água foi constatado em três solos tropicais com características químicas e fisicas distintas (Firmino et al., 2008). Segundo esse autor, o imazapyr apresenta alta mobilidade nos solos muito argiloso, franco-argiloarenoso e areia-franca e o movimento ascendente do imazapyr acontece por capilaridade, junto com o movimento da água no perfil do solo. Assim, em solos que apresentam baixa sorção do imazapyr os riscos com a lixiviação e a biodisponibilização para plantas não-alvo são maiores.

Apesar de não registrado para essa finalidade, o imazapyr destaca-se como alternativa para o controle de plantas daninhas aquáticas, por demonstrar elevado potencial para uso nesses ambientes (Carbonari et al., 2003, 2004). Entretanto, pesquisas sobre a viabilidade técnica, ecológica e social de sua utilização em ambientes aquáticos são necessárias, levando-se em conta sua persistência e dinâmica no ambiente. A alta persistência no ambiente e a lixiviação do imazapyr, aliado à sua baixa sorção em determinados solos, podem restringir o uso desse produto. A elevada atividade residual do imazapyr pode impedir temporariamente a semeadura de culturas de interesse agronômico nas áreas tratadas com esse herbicida (Agostinetto et al., 2001), o que limita sua utilização em sistemas de produção em que os princípios da rotação de culturas e diversificação da produção são preconizados.

O herbicida imazapyr apresentou a seguinte ordem de sorção nos substratos: muito argiloso $>$ franco-argilo-arenoso $>$ areia-franca $>$ areia lavada. Entre as características dos solos, o teor de argila e o teor de $\mathrm{CO}$ e de óxidos de ferro são os que interferem na sorção de imazapyr. Contudo, há necessidade de se estimar a participação de cada um desses fatores do solo, juntamente com o $\mathrm{pH}$, na sorção de imazapyr em solos tropicais.

\section{LITERATURA CITADA}

AGOSTINETTO, D.; LAMEGO, F. P.; PINTO, J. J. O. Ação residual do herbicida imazapyr aplicado em canal de irrigação na cultura do arroz. R. Bras. Agroci., v. 7, n. 3, p. 181-188, 2001.

AHRENS, W. H. (Ed.). Herbicide handbook. Champaign: Weed Science Society of America, 1994. 352 p.

CARBONARI, C. A.; MARTINS, D.; TERRA, M. A. Controle de Brachiaria subquadripara e Brachiaria mutica através de diferentes herbicidas aplicados em pós-

emergência. Planta Daninha, v. 21, n. 1, p. 79-84, 2003.

CARBONARI, C. A. et al. Controle químico de Panicum repens e Paspalum repens. Planta Daninha, v. 22, n. 3, p. 453-460, 2004.

COHEN, S. Z. et al. Potential for pesticide contamination of groundwater resulting from agricultural uses. In: KRUGER, R. F.; SEIBER, J. N. Treatment and disposal of pesticide wastes. Washington: American Chemistry Society, 1984. p. 297-325.

CURRAN, W. S. et al. Photolysis of imidazolinone herbicides in aqueous solution and on soil. Weed Sci., v. 40, n. 1, p. 143-148, 1992.

FIRMINO, L. E. et al. Movimento do herbicida imazapyr no perfil de solos tropicais. Planta Daninha, v. 26, n. 2, p. 223-230, 2008.

GENNARI, M.; NÉGRE, M.; VINDROLA, D. Adsorption of the herbicides imazapyr, imazethapyr and imazaquin on soils and humic acids. J. Environ. Sci. Health, v. 33, n. 5, p. $547-567,1998$.

GUSTAFSON, D. I. Groundwater ubiquity score: A simple method for assessing pesticide leachibility. Environ.

Toxicol. Chem., v. 8, n. 4, p. 339-357, 1989. 
INOUE, M. H. et al. Critérios para avaliação do potencial de lixiviação dos herbicidas comercializados no Estado do Paraná. Planta Daninha, v. 21, n. 2, p. 313-323, 2003.

ISMAIL, B. S.; AHMAD, A. R. Attenuation of the herbicidal activities of glufosinate-ammonium and imazapyr in two soils. Agric. Ecosyst. Environ., v. 47, n. 4, p. 279285, 1994.

LI, H. et al. Sorption and desorption of pestides by clay minerals and humic acid-clay complexes. Soil Sci. Soc. Am., v. 67, p. 122-131, 2003.

MALLIPUDI, N. M. et al. Photolysis of imazapyr (AC 243997) herbicide in aqueous media. J. Agric. Food Chem., v. 39, n. 2, p. 412-417, 1991.

MANGELS, G. Behaviour of the imidazolinone herbicides in soil - a review of the literature. In: SHANER, D. L.;

O'CONNOR, S. L. (Eds.). The imidazolinone herbicides Boca Raton: CRC, 1991. p. 191-209.

PROCÓPIO, S. O. et al. Sorção do herbicida atrazine em complexos organominerais. Planta Daninha, v. 19, n. 3, p. $391-400,2001$

PUSINO, A.; PETRETTO, S.; GESSA, C. Adsorption and desorption of imazapyr by soil. J. Agric. Food Chem., v. 45 , n. 3 , p. $1012-1016,1997$.

PUSINO, A. et al. Sorption of primisulfuron on soil, and inorganic and organic soil colloids. Eur. J. Soil Sci., v. 55, n. 1 , p. $175-182,2004$.

RODRIGUES, B. N.; ALMEIDA, F. S. Guia de herbicidas. Londrina: 2005. 591 p

SI, Y. et al. Influence of organic amendment on the adsorption and leaching of ethametsulfuron-methyl in acidic soils in China. Geoderma, v. 130, n. 1, p. 66-76, 2006
SILVA, C. M. M. et al. Exsudação radicular de imazapyr por mudas de eucalipto cultivadas em solução nutritiva.

R. Árvore, v. 29, n. 6, p. 915-920, 2005.

SINDAG. Dados de mercado: produtos em linha de comercialização - outubro de 2006. Disponível em: (www.sindag.com.br/dados_mercado.php). Acesso em: 19 de julho de 2006 .

SOUZA, A. P. et al. Efeito do oxyfluorfen, 2,4-D e glyphosate na atividade microbiana de solos com diferentes texturas e conteúdo de matéria orgânica. Planta Daninha, v. 14, n. 1, p. $55-64,1996$

SOUZA, A. P. et al. Lixiviação de glyphosate e imazapyr em solos com diferentes texturas e composição química IMétodo do Bioensaio. Planta Daninha, v. 18, n. 1, p. 5-16, 2000 .

SOUZA, G. V. R. et al. Exsudato radicular de imazapyr aplicado sobre mudas de diferentes clones de eucalipto. Planta Daninha, v. 24, n. 1, 2006

VIEIRA, E. V. et al. Estudo da adsorção/dessorção do ácido 2,4 diclorofenoxiacético (2,4-D) em solo na ausência e presença de matéria orgânica. Química Nova, v. 22, n. 3, p. $305-308,1999$

WANG, Q.; LIU, W. Correlation of imazapyr adsorption and desorption with soil properties. Soil Sci., v. 164, n. 6, p. 411-416, 1999

WIDERSON, M. R.; KIM, K. D. The pesticide contamination prevention act: setting specific numerical values. Sacramento: California Dep. Food and Agric., Environmental Monitoring and Pest Manage, 1986. $287 \mathrm{p}$. 